\title{
The Integration of Moral Education and a Professional Course to Better Strengthen Moral Education and Cultivate Students
}

\author{
Genfa Yu and Guangyong Zhu*
}

\author{
No. 100 Haiquan Road, Shanghai Institute of Technology, China \\ *Corresponding author. Email:zgy012@126.com
}

\begin{abstract}
Strengthening moral education and cultivate students are the fundamental task for higher education. It is necessary to persist in taking morality and cultivating students as the key point, and to make ideological and moral education penetrate the whole teaching process. Flavor compounds Chemistry is a professional compulsory course in Shanghai Institute of Technology. In order to further implement the fundamental task of cultivating students and strengthening moral education, moral and virtue education were integrated into the teaching process of flavor compounds chemistry in this paper. By the integration of moral education and flavor compounds chemistry, students can not only learn more in-depth professional knowledge, but also can be inspired to be diligent and studious, and can be fostered the spirit to bear hardship and make perfection more perfect. Furthermore, strong will, perseverance, awareness of legal system and rules, and compliance with discipline and regulations were cultivated.
\end{abstract}

Keywords: Professional course, Moral education, Cultivate students.

\section{INTRODUCTION}

Strengthening moral education and cultivate students are the fundamental task for higher education [1]. From the perspective of the social demand for people, society not only need people with high skills, but also need highly qualified people. Therefore, strengthening the ideological and moral education has become an irreversible trend. In order to realize full-process education and all-around education, it is necessary to persist in taking morality and cultivating students as the key point, and to make ideological and moral education penetrate the whole teaching process. All the university teachers should fulfill higher-educational teaching responsibilities [2]. They should undertake the mission of imparting knowledge, cultivating and educating students, and improving the national quality. First of all, a teacher should foster students with virtues, and teach students how to behave and how to become a virtuous person. Secondly, a teacher should teach them to learn broad and practical knowledge. The ideological and political courses play a crucial role in the university students' growth as a main channel to improve their moral and ideological level. Morality and virtue can be taught not only in ideological and political courses, but can also in science and engineering courses. The ideological guidance and moral value shaping can be incorporated into the teaching process of each course to build a cohesion and coordination between professional education and ideological education.

Flavor compounds Chemistry is a professional compulsory course which has been opened for students whose majors are light chemical engineering or flavor and fragrance technology and engineering in Shanghai Institute of Technology for many years. The content of this course is mainly about the basic knowledge of flavor. It tells the basic concept and terminology of flavors and their raw materials; classification, safety, durability and stability of flavors; the odor characteristics of aroma materials of natural and synthetic origin and the applications these raw materials in blending flavors; the chemical structure and preparation method of synthetic aroma materials; the main ingredients of common natural aroma materials and the manufacturing processes for natural aroma materials. The teaching content of the course meets the needs for the development of contemporary university students majoring in flavor and 
fragrance technology and engineering. However, the traditional flavor compounding chemistry teaching lays much more emphasis on the imparting of professional knowledge, while the educational function is slightly ignored. In order to further implement the fundamental task of cultivating students and strengthening moral education, moral and virtue education can be integrated into the teaching process of flavor compounds chemistry.

\section{INSPIRE STUDENTS TO BE DILIGENT, STUDIOUS, GOOD AT THINKING, AND DEDICATED TO RESEARCH}

In the background of the first chapter, the "two and a half noses" of China, who have made great contributions to China's fragrance and flavor industry, are introduced and depicted in class. The two noses refer to the Wang brothers (Wang Qingru, Wang Qingquan, Wang Qinghua) and the Ye brothers (Ye Xinnong, Ye Shiyu, Ye Zhongtao), half of the nose refers to Dai Ziying who worked in the original Jianchen Perfume Factory [3]. They were diligent and good at thinking. Their persistence in learning, diligent study and selflessness in the front line of scientific research have made outstanding contributions to the development of fragrances and flavors in China. In 1929, the three Ye brothers engaged in the research of flavor and fragrance formulas and created the original Ye perfumery technique. In 1959, a group of perfumers headed by Ye Xinnong discussed the odor classification of aroma materials. They proposed that the aroma materials can be divided into two categories: floral and non-floral types [4]. The floral type can be further divided into eight notes and the corresponding representative flowers are shown in Fig. 1(a). The non-floral type can be further divided into twelve notes as shown in Fig. 1(b)

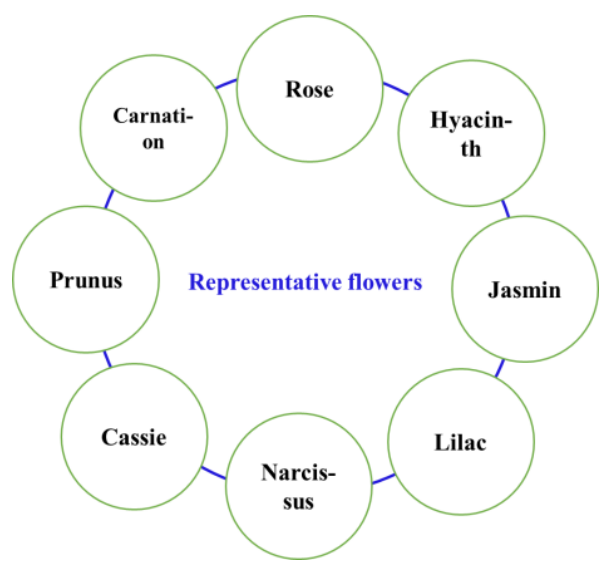

(a)

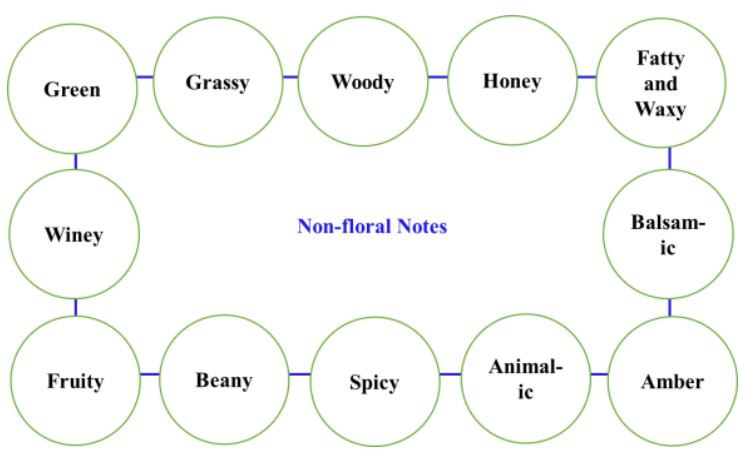

(b)

Figure 1 The eight kinds of representative flowers and the twelve kinds of non-floral notes

These notes are listed in sequence and form two rings which can be used to illustrate the meaning of the forward and backward links between them [5]. It is an original scientific theoretical basis for blending flavors and fragrances in China. Their deeds have inspired students to be hardworking and dedicated to research.

\section{CULTIVATE STRONG WILL, SURENESS WORKING STYLE, AND PERSEVERANCE}

When identifying the odor characteristics of the natural and synthetic aroma materials, students are required to repeatedly smell to grasp and remember the aroma of each material. By mastering the aroma characteristics, students can lay a solid foundation for the creation of flavors in the future. More than 400 common flavor materials are required to be distinguished and their odor characteristics should be remembered in this curriculum [6]. Therefore, it is impossible to grasp the odor characteristics of so many aroma materials in a short time. Furthermore, the aroma of some raw materials is difficult to remember. Only by repeated smelling can students grasp the odor characteristics. The process will not be easy or quick. It will require a long time of hard work. With the experience of hardships and endurances, students can cultivate strong will and have sureness working style. With the experience of repeated smelling, students can study assiduously and perseveringly, and can also learn how to smooth away difficulties.

\section{FOSTER STUDENTS THE SPIRIT TO BEAR HARDSHIP AND HARD WORK}

Although the finished products of flavors and fragrances have pleasant smells, the odors of some raw materials (see Fig. 2) for blending them are unpleasant and even irritant [6]. 
Acids $(\mathrm{n}=0-8)$

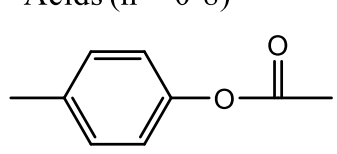

P-cresyl acetate

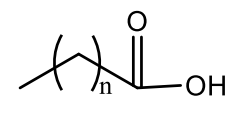<smiles>c1ccc2[nH]ccc2c1</smiles>

Indole

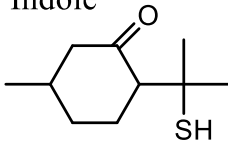

Mehtha-8-thiol-3-one
Figure 2 Some raw materials with unpleasant or irritant odors

Acids are also common aroma materials for blending flavors. Aliphatic acids from $\mathrm{C} 2$ to $\mathrm{C} 10$ are usually uses to accentuate certain aroma characteristics in flavor compositions, for example, acids from $\mathrm{C} 3$ to $\mathrm{C} 8$ can be used to accentuate fruity notes, acids from $\mathrm{C} 4$ to $\mathrm{C} 10$ can be used to accentuate cheese notes $[7,8]$. The aliphatic acids such as acetic acid, butyric acid, 2-methy-butyric acid, hexanoic acid, butyric acid, have strong and pungent unpleasant odors and acid tastes. They are irritating to the nasal cavity when smelling them. Although hexanoic acid is important for blending flavors used in cheese, baked goods, hard candy, frozen dairy and so on, it has a sickening unpleasant odor, somewhat smelly feet. At higher dilutions, indole has a floral note. Minor indole contributes strongly to the typical jasmine fragrance. However, at high concentration indole has an unpleasant, fecal odor. P-cresyl acetate is another material with heavy fecal odor. However, it has the effect of increasing rich floral aroma. P-cresyl acetate is suitable for blending narcissus, yellow daffodil and Jasminum grandiflorum fragrances. It can also be used in blending flavors such as bananas, cherries and nuts. Mehtha-8-thiol-3-one has a characteristic odor of black currant. At low concentrations, mehtha-8-thiol-3-one can produce a diffusive and very fresh top note and confer a very special character to perfume. It has been widely used for blending flavors such as mango, oolong tea, green tea, grapefruit, peach, tropical fruit and so on [9]. However, it has a strong unpleasant and aggressive odor at high concentrations. For these materials with unpleasant and (or) irritant odors, it needs bear hardship to accurately grasp their odor characteristics. Accurately grasping the odor characteristic of these material is the basic requirement for becoming a flavorist in future. During the process of smelling these materials, the spirit to bear hardship and hard work can be fostered for students.

\section{FOSTER STUDENTS THE SPIRIT TO MAKE PERFECTION MORE PERFECT}

In the process of learning synthetic aroma raw materials, odor characteristics and chemical structures are the key points for students to master. After students have mastered the odor characteristics and chemical structures of synthetic raw materials, they are encouraged to explore the relationship between odors and structures to further expand their horizons. In some cases, some aroma materials which are completely different in structure have similar odors, and conversely some aroma materials which are similar in structure have dramatically different odors [10]. These issues can elicit thinking and foster students the spirit to make perfection more perfect.

1,8-p-Menthadien-6-one (also called carvone, see Fig. 3), $\mathrm{C}_{10} \mathrm{H}_{14} \mathrm{O}$, has two optical isomers, which differ considerably in their sensory properties. (+)-carvone exhibits odor reminiscent of caraway, while (-)-carvone exhibits odor of spearmint. Both (-) - and (+)-carvone are used in many beverages and foods. Especially, (-)-carvone is also used in oral hygiene products [11]

2,4-Dimenthyl-3-cyclohexene-1-carboxaldehyde (Trade name: Triplal), often used for perfuming

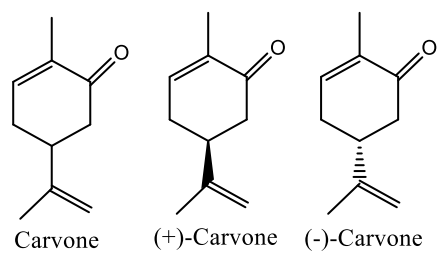

Figure 3 The chemical structure formula of carvone

Household products and cosmetic preparations, has a strongly green note. Cis-3-hexen-1-ol (also called leaf alcohol), which has intense green note reminiscent of freshly cut grass, is also often used to obtain natural green notes in flavors and perfumes. Although one of them is classified into aldehyde and the other is classified into alcohol (see Fig. 4), they all have green note $[8,11]$.

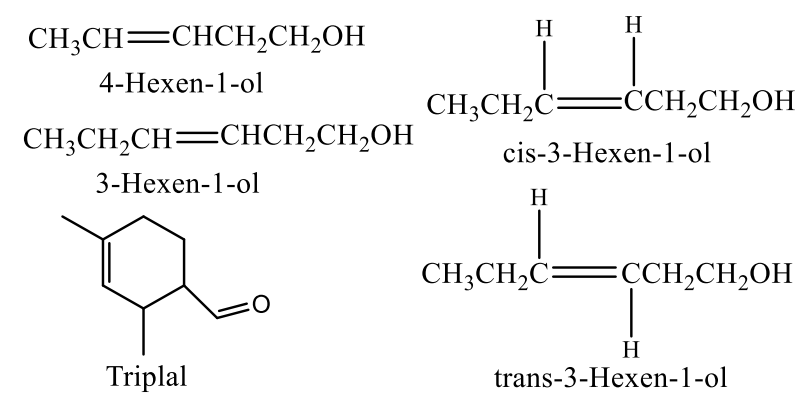

Figure 4 The chemical structure formula of triplal, 4-hexen-1-ol and 3-hexen-1-ol

3-Hexen-1-ol and 4-hexen-1-ol have the same molecular formula, $\mathrm{C}_{6} \mathrm{H}_{12} \mathrm{O}$. Only the position of the double bond is different in their chemical structural formula (see Fig. 4). 4-Hexen-1-ol has a pungent oily odor, while 3-hexen-1-ol has grassy green aroma. Due to the existence of a double bond in the molecular structure, 3-hexen-1-ol has two cis-trans isomers. Compared with trans-3-hexen-1-ol, cis-3-hexen-1-ol has an intense grassy leafy odor and therefore also called leaf alcohol $[8,11]$. 
Vanillin, a main aroma ingredient of Vanilla planifolia and V. tahitensis pods, has a typical vanilla odor. It has been widely used in foods such as ice cream, bakery products, confectioneries, and chocolate [11,12]. Ethyl vanillin is a homologue of vanillin. When the methyl group in vanillin molecule is replaced by an ethyl group, vanillin can be converted to ethyl vanillin (see Fig. 5).<smiles>CCOc1ccc(C=O)cc1OCC</smiles>

Figure 5 The chemical structure formula of vanillin and ethyl vanillin

Like vanillin, ethyl vanillin also has an intense vanilla odor. However, its flavoring power is two to four times stronger than vanillin. A small difference in molecular structure can cause huge changes in odor power.

Propenylguaethol,

also

called

2-ethoxy-5-(1-propen-1yl)-phenol, is an artificial aroma material which has not been found in nature. It has a vanilla-like odor and flavor. Although propenyguaethol and vanillin are different in structure (see Fig. 6), they all have similar odor reminiscent of vanilla [11].

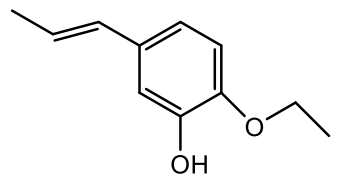

Propenylguaethol

Figure 6 The chemical structure formula of propenylguaethol

Maltol has a sweet caramel-like aroma reminiscent of freshly baked cakes. It can present sweet and caramel notes in flavors and can be used as a taste intensifier. Just like vanillin and ethyl vanillin, Ethyl maltol is a homologue of maltol (see Fig. 7). Ethyl maltol has a very sweet caramel-like aroma and is four to six times more potent than maltol $[8,11]$.<smiles></smiles>

Figure 7 The chemical structure formula of maltol and ethyl maltol

Methylcyclopentenolone, also called 2-hydroxy-3-methyl-2-cyclopenten-1-one, has three tautomers as shown in Fig. 8.

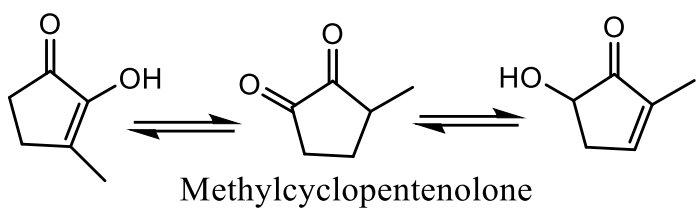

Figure 8 The three tautomers of methylcyclopentenolone

Although the chemical structure of methylcyclopentenolone is different from the structures of maltol and ethyl maltol, methylcyclopentenolone also has a sweet odor [11].

By the exploration of the relationship between odors and structures, students can not only learn more in-depth professional knowledge, but also can be fostered the spirit to make perfection more perfect.

\section{CULTIVATE STUDENT'S AWARENESS OF LEGAL SYSTEM AND RULES, AND STRENGTHEN THE CONCEPT OF OBSERVING DISCIPLINE AND REGULATION}

When telling the safety and regulatory issues of flavors, the incident of "One Drop Aroma" will be discussed in the class. "One Drop Aroma" is a salty flavor and a kind of food additive. It is often used as a condiment to make rice noodles, hot pot, malatang and other food. The main ingredients are enzymatic meat extract, hydrolyzed vegetable protein, amino acids, etc. It is reported that only one drop is needed to turn a pot of water into a savory meaty soup-stock. According to Food Additive Production Supervision and Management Regulations, the words "food additives" should be marked on the label of the product. It was said that a considerable part of "One Drop Aroma" and similar products sold on the market were of unknown origin and their labels were unclear. Quite a few of these products were sold to catering enterprises. Therefore, people are more concerned about whether these products are harmful and whether they can be eaten. Most of the consumers don't know the ingredients of "One Drop Aroma", and they think that the food additives are chemicals, which may be harmful to the human body. It has become the focus of debate whether "One Drop Aroma" is poisonous. According to a report in China Quality News, food experts concluded that the "One Drop Aroma" of unknown origin was produced through a synthetic reaction and a direct blending of chemicals. Long-term excessive consumption of some synthetic chemicals will endanger human health. The social phenomena such as "One Drop Aroma" are taken as examples to further enhance the students' social responsibility and clarify the social morality and scientific spirit that should be possessed when they engage in the professional work of 
flavor and fragrance. By describing the safety regulations, management regulations of flavors and international regulatory agencies such as FEMA (Flavor and Extract Manufacturers Association of the United States), COE (Council of Europe \& Experts on Flavoring Substances), FDA (Food and Drug Administration), etc., students can get to know the information about international regulations on the management of flavor compounds. By telling the National Food Safety Standard and the Standard of Using Food Additives (GB2760), students can further understand the regulations regarding flavors, which aroma materials can be used, which aroma materials cannot be used in China. The concept of aroma material dosage is a very important concept. A deep understanding of the amount of aroma materials used in products is critical to safety. The amount of aroma materials in the terminal products must be strictly distinguished from the amount aroma materials in the flavor formula. When selecting aroma materials for designing a flavor formula, students are required to strictly pay attention to the amount of aroma materials, which must meet the requirements of GB2760. Although an aroma material used in a certain amount are safe, there may be potential safety hazards if the dosage is too high. The aroma material maximum amount in terminal products should not be exceeded to ensure the safety of the products. This learning process can cultivate student's awareness of the legal system and rules, enhance the concept and awareness of observing discipline and law, and improve students' ability to distinguish right from wrong.

\section{CONCLUSION}

Flavor compounds chemistry is a professional basic course for students majoring in flavor and fragrance engineering and technology. By integrating ideological education, students can be ideologically educated while acquiring professional knowledge of flavor. It can bring about a coordinated development of professional knowledge and ideological education.

\section{ACKNOWLEDGMENT}

This research was financially supported by the Pilot Program on key courses in Shanghai Institute of
Technology

\section{REFERENCES}

[1] Z. Liu, Y. Cui, S. Liu, X. Yang, S. Wang, Design of the "curriculum ideological and political education" in organic chemistry, Univ. Chem. 35 (2020) 31-35.

[2] G. Han, R. Liu, J. Guan, Exploration of organic chemistry teaching under the background of course ideology and politics, Univ. Chem. 34 (2019) 56-60.

[3] X. Lin, The World of Fragrance, Chemical Industry Press, Beijing, 2018.

[4] G. Yu, G. Wu, Perfumery Technology, China Light Industry Press, Beijing, 2007.

[5] C. Zhang, Q. Wang, Perfumery, China Light Industry Press, Beijing, 1989.

[6] Y. Zhou, Z. Xiao, Preparation Technology of Flavors, China Textile and Apparel Press, Beijing, 2007.

[7] G. Zhu, G. Yu, A pineapple flavor imitation by the note method, Food Sci. Tech. (2020)DOI: https://doi.org/10.1590/fst.26019.

[8] H. Surburg, J. Panten, Common Fragrance and Flavor Materials, Wiley-VCH Verlag GambH \& Co, Weinheim, 2006.

[9] G. Zhu, Z. Xiao, G. Zhu, Preparation, characterization and the release kinetics of mentha-8-thiol-3-one- $\beta$-cyclodextrin inclusion complex. Polym. Bull. 74 (2017) 2263-2275.

[10] K.J. Rossiter, Structure-odor relationships, Chem. Rev. 96 (1996) 3201-3240.

[11] G.A. Burdock, Fenaroli's Handbook of Flavor Ingredients, CRC Press, Boca Raton, 2010.

[12] G. Zhu, Z. Xiao, Creation and imitation of a milk flavour, Food Funct. 8 (2017) 1080-1084 